\title{
Osteopetrosis infantil maligna
}

\section{Malignant Infantile osteopetrosis}

\author{
Vomero A. ${ }^{a}$, Tapie A. ${ }^{b}$, Arroyo C. ${ }^{a}$, Raggio V. ${ }^{b}$, Peluffo G. ${ }^{a}$, Dufort G. ${ }^{c}$ \\ ${ }^{a}$ Clínica Pediátrica. Facultad de Medicina. Universidad de la República. Uruguay

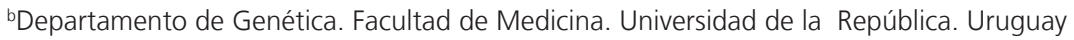 \\ 'Centro Hematooncológico Pediátrico, Centro Hospitalario Pereira Rossell, Uruguay
}

Recibido: 22 de noviembre de 2018; Aceptado: 11 de marzo de 2019
Palabras clave:

Osteopetrosis Infantil Maligna;

Trombocitopenia;

Falla medular;

Esclerosis ósea;

Hepatosplenomegalia compromiso sensorial visual y auditivo e infecciones a repetición. El diagnóstico fue confirmado mediante estudio genético, el cual identificó 2 mutaciones heterocigotas en el gen TCIRG1. Se realizó trasplante de precursores hematopoyéticos, sin haber presentado recuperación hematológica, falleciendo por enfermedad veno oclusiva. Discusión: La OIM es una enfermedad inusual, grave y de inicio temprano, siendo necesario un elevado índice de sospecha ante hepatoesplenomegalia y falla medular. El diagnóstico temprano y el trasplante de precursores hematopoyéticos son las únicas intervenciones potencialmente curativas de esta entidad letal.

\begin{abstract}
Introduction: Malignant Infantile Osteopetrosis (MIOP) is a rare and severe genetic disorder due to abnormal osteoclast activity. Objective: To report an infant who presented Malignant Infantile Osteopetrosis, reviewing the most relevant diagnostic and therapeutic aspects. Clinical case: A tenmonth-old male infant with diagnosis of MIOP confirmed after presenting thrombocytopenia and visceromegaly. He was the first child of non-consanguineous parents, and among the findings, he presented severe hepatosplenomegaly, thrombocytopenia, and anemia; visual and hearing impairment, and repeated infections. The diagnosis was confirmed by genetic study, which identified two heterozygous mutations in the TCIRG1 gene. Hematopoietic stem cells were transplanted without hematological recovery. The patient died due to occlusive venous disease. Discussion: MIOP is a rare, severe, and early-onset disease, with a high rate of suspicion necessary in the presence of hepatosplenomegaly and bone marrow failure. Early diagnosis and hematopoietic stem cells transplantation are the only potentially therapeutic interventions of this lethal entity.
\end{abstract}

\section{Keywords:}

Malignant Infantile

Osteopetrosis;

Thrombocytopenia;

Bone Marrow Failure;

Osteosclerosis;

Hepatosplenomegaly 


\section{Introducción}

La Osteopetrosis es un conjunto de trastornos genéticos que determinan esclerosis del esqueleto ${ }^{1}$, siendo también conocida como Enfermedad de AlbersSchonberg, quien realizó la primera descripción de la forma benigna de la enfermedad en $1904^{2,3}$. Se conocen al menos 10 variedades de Osteopetrosis, con distintos modos de herencia y severidad, abarcando desde formas asintomáticas a fatales ${ }^{1,2}$. Las presentaciones más severas se heredan de forma autosómica recesiva y aparecen en la infancia, denominándose Osteopetrosis Infantil Maligna (OIM), mientras que las formas más leves se observan en adultos y son de herencia autosómica dominante ${ }^{2,4,5}$. Su incidencia se estima en 1 en 250.000 recién nacidos en la forma autosómica recesiva y 1 en 20.000 en la forma autosómica dominante ${ }^{2,6}$.

La OIM es un trastorno debido a defectos en la reabsorción ósea ${ }^{6}$, radicando su patogenia en la alteración en la diferenciación o función osteoclástica, lo que impide la normal resorción y remodelación ósea ${ }^{1,2,4,6-9}$. Esto origina un exceso de sustancia osteoide, dando lugar a una disminución progresiva del espacio medular óseo, sitio donde se desarrolla la hematopoyesis ${ }^{6,8,10}$. Las radiografías revelan esclerosis ósea difusa ${ }^{4}$. La reducción paulatina de la producción de sangre determina la aparición de anemia, plaquetopenia, leucocitos inmaduros y eritroblastos en sangre periférica, con la consiguiente hepatoesplenomegalia progresiva por hematopoyesis extramedular compensatoria ${ }^{2,4,8,9}$.

El diagnóstico se basa en los hallazgos clínicos y radiológicos, y su confirmación se realiza mediante análisis genético-molecular, que permite, además de caracterizar la alteración funcional específica, definir estrategias terapéuticas ${ }^{1,2,11}$. El único tratamiento curativo es el trasplante alogénico de médula ósea, el cual debe ser precoz, para evitar el fallo medular severo y las graves secuelas neurosensoriales de la esclerosis ósea progresiva $a^{2,7,8,12}$.

\section{Objetivo}

El objetivo de estae trabajo es reportar el caso clínico de un lactante en quien se documentó una Osteopetrosis Infantil Maligna, revisando aspectos diagnósticos y terapéuticos más relevantes.

\section{Caso clínico}

Lactante menor, sexo masculino, producto de primera gestación de padres sanos de 23 años, no consanguíneos, sin antecedentes familiares patológicos. El embarazo no tuvo complicaciones, naciendo un niño de término, de peso adecuado para la edad gestacional, en quien se constató cornaje nasal.

A los 15 días de vida fue hospitalizado por bronquiolitis aguda, ingresando a la Unidad de Cuidados Intensivos por desarrollo de una falla respiratoria aguda. Recibió asistencia ventilatoria mecánica prolongada, siendo traqueostomízado. Permaneció en esta unidad durante 5 meses, cursando múltiples infecciones bacterianas invasivas.

Desde el punto de vista hematológico, presentó desde su el ingreso plaquetopenia severa (cifras mínimas de $16.000 / \mu \mathrm{L}$ ) agregando posteriormente anemia normocitica-normocrómica y hepatoesplenomegalia grado III. Recibió en múltiples oportunidades transfusiones de glóbulos rojos y plaquetas. El mielograma mostró una médula ósea de densidad normal y aspecto polimorfo, con una resistencia ósea significativamente aumentada. Se realizaron radiografías de cráneo y huesos largos, apreciándose un marcado aumento de la densidad ósea del diploe, y afectación esclerosa de la base (figuras 1A y 1B). La tomografía de cráneo y órbitas objetivó un aumento de la densidad ósea del cráneo (figura 1C). En lo metabólico se constataron hipocalcemias sintomáticas que requirieron suplementación. En lo neurológico se evidenció hipotonía global, y compromiso sensorial visual y auditivo. El fondo de ojo mostró atrofia papilar bilateral, y los potenciales evocados visuales no identificaron potenciales corticales correspondientes a la vía retino-calcarina. Los potenciales auditivos mostraron hipoacusia bilateral leve. La Resonancia magnética de cráneo identificó malformación ósea de la base del cráneo.

De la analítica de laboratorio destacó anemia normocítica normocrómica $(\mathrm{Hb} 6,75 \mathrm{~g} / \mathrm{dl})$, Plaquetopenia $47.700 / \mu \mathrm{L}, 6 \%$ eritroblastos y Reticulocitosis relativa $21 \%$. La cuantificación de inmunoglobulinas y poblaciones linfocitarias fueron normales.

En presencia de fallo hematológico asociado a vísceromegalias y esclerosis del esqueleto, se planteó diagnóstico de probable defecto de la reabsorción ósea y, considerando la forma de presentación clínica severa y precoz, una OIM. Se envió una muestra de ADN al Laboratorio de Biología Molecular de Universitatklinikum Ulm en Alemania, Centro de Referencia mundial para el estudio de esta patología, encontrándose 2 mutaciones en el gen TCIRG1 (11q13.2), en heterocigosis compuesta: c.797delA (p.Glu266GlyfsX12) y c.1387ins (GCTTCATCTACAACGfs) (p.Glu463Glyfs, con lo que se confirmó el diagnóstico planteado. Se realizó un trasplante de progenitores hematopoyéticos (TPH) a los 10 meses de edad. Por tratarse de un hijo único recibió un TPH haploidéntico (madre donante), con delección de linfocitos $\mathrm{T}$ (selección negativa de CD3+ con tecnología ClinMacs) y condicionamiento mieloablativo con Busulfan, Fludarabina y Thiotepa. 


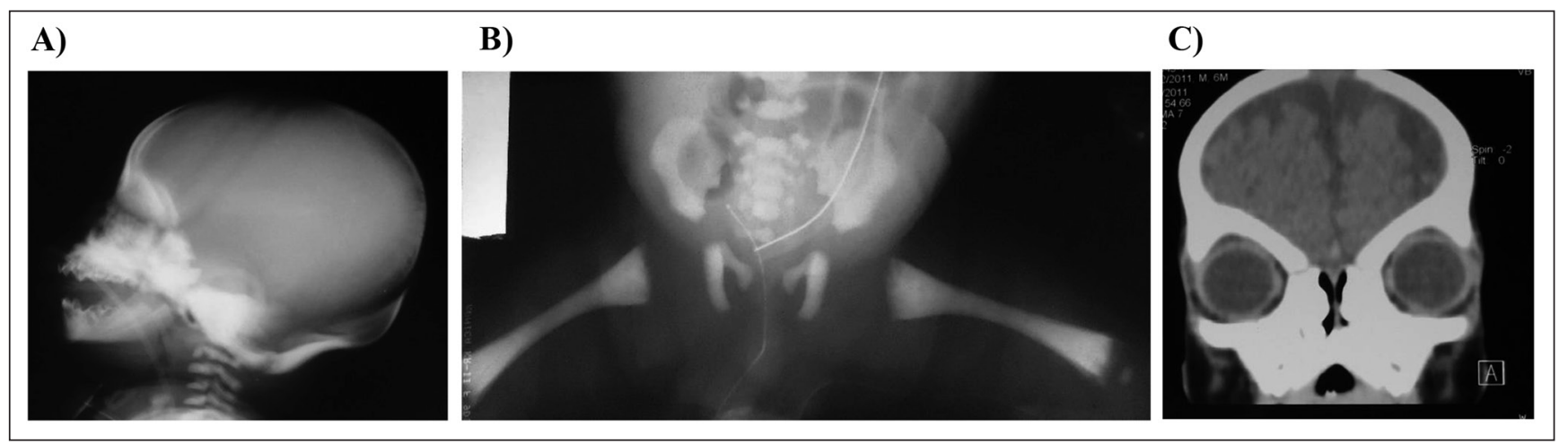

Figura 1. A) Radiografía lateral de cráneo en la que se visualiza esclerosis de la base de cráneo. B) Radiografía de huesos largos, los cuales se aprecian densos, radio-opacos, sin cavidad medular. Vértebras y pelvis con densidad aumentada. C) Tomografía computada de cráneo, donde destaca un marcado aumento de la densidad ósea.

El paciente falleció por enfermedad veno-oclusiva hepática, con falla orgánica múltiple, sin haberse objetivado recuperación hematológica.

\section{Discusión}

Nos encontramos frente a un lactante con plaquetopenia, que en la evolución agrega falla medular y vísceromegalias, asociadas a esclerosis del esqueleto, en quien se realizó el diagnóstico presuntivo de OIM, el cual fue confirmado mediante estudio molecular.

La principal manifestación de la enfermedad es hematológica. El fracaso de la remodelación de los huesos en crecimiento determina la invasión de los espacios medulares por exceso de sustancia osteoide. Como consecuencia, la insuficiencia medular progresiva deriva en anemia grave, trombocitopenia y leucoeritroblastosis. La hepatoesplenomegalia es manifestación de la hematopoyesis extramedular compensatoria ${ }^{2,4,5,8}$.

Clínicamente pueden presentar un fenotipo particular, dado por frente y fontanelas amplias, nariz aplanada y encías gruesas. También pueden asociar craneosinostosis, macrocefalia progresiva con abombamiento frontal, exoftalmos e hipertelorismo ${ }^{2,3,4,8}$.

Un elemento significativo es la presencia de cornaje nasal desde el nacimiento. Se describe la respiración ruidosa, originada por el compromiso de huesos de base de cráneo, coanas y mandíbula, lo que determina una obstrucción de vía aérea superior ${ }^{4}$. Puede ser un elemento de sospecha diagnóstica en el primer mes de vida en un paciente con anemia normocítica normocrómica o plaquetopenia inexplicada ${ }^{3}$. Los déficits neurosensoriales son frecuentes por estrechamiento de los orificios de los nervios craneales, que determinan compresión vascular y nerviosa $a^{4-6,8,11}$. El nervio óptico es el principal afectado, lo que genera pérdida parcial o total de visión. Pueden presentar movimientos oculares anormales o nistagmus ${ }^{3}$. Más raramente se observa afectación de los nervios auditivo, facial y olfatorio ${ }^{2,4}$.

El paciente manifestó hipocalcemias sintomáticas desde el nacimiento. Este fenómeno es frecuente, debido a la defectuosa función osteoclástica, que determina disturbios en la homeostasis del calcio ${ }^{4}$. Suelen ser sintomáticas, de aparición precoz, con reservas corporales elevadas de calcio ${ }^{4}$. En casos graves pueden determinar tetania e hiperparatiroidismo secundario ${ }^{2}$.

La elevada incidencia de infecciones es característica. Se deben a alteraciones a nivel de la inmunidad celular. Es frecuente encontrar disfunciones de monocitos y neutrófilos y disminución en la actividad «natural killer ${ }^{8}$.

Frente a un cuadro clínico sugestivo de OIM se deben solicitar estudios radiológicos ${ }^{1,3}$. Los hallazgos característicos son huesos uniformemente densos, escleróticos y radio-opacos; imagen de hueso dentro de hueso, especialmente en vértebras y falanges, y esclerosis focal de la base de cráneo, pelvis y vértebras. En las metáfisis de los huesos largos se pueden observar bandas radiolúcidas y desaparición de la cavidad medular ${ }^{2,5,8}$.

El diagnóstico confirmatorio se realiza mediante el estudio molecular, que tiene implicancias terapéuticas, pronósticas y para asesoramiento genético ${ }^{2,11}$. Se realizó secuenciación de los genes TCIRG1 y CLCN7, constatándose la presencia de dos mutaciones en trans en el gen TCIRG1 (heterocigoto compuesto): una deleción en el exón 8 que lleva a un cambio del marco de lectura, generando un codón stop prematuro (proteína truncada), y una inserción de 15 pares de base en el exón 12, que ocasiona un cambio en el marco de lectura en los codones que flanquean la inserción y la adición de 4 aminoácidos. Si bien ambas mutaciones no han sido descritas previamente, se deben considerar probablemente patogénicas, ya que alteran severamente la estructura de la proteína y se pueden asociar a pérdida de función del gen. 
Las mutaciones en el gen TCIRG1 determinan el $50 \%$ de los casos de OIM ${ }^{1,4,10}$. Este gen codifica una subunidad específica de la bomba de protones de los osteoclastos; su disfunción genera alteraciones en la acidificación, necesaria para la correcta función de la reabsorción ósea ${ }^{4,5}$. Los portadores de mutaciones en este gen son candidatos para trasplante de médula ósea en forma urgente, por la severidad de la afección y la potencial respuesta a este tratamiento, ya que se trata de osteoclastos disfuncionales en una matriz ósea normal. Si bien esta mutación no se acompaña de enfermedad neurodegenerativa, las guías internacionales recomiendan la valoración neurológica, la realización de electroencefalograma y resonancia nuclear magnética $^{1}$.

La evolución natural es progresiva, con muerte generalmente en la primera década de la vida ${ }^{2,6}$, siendo rara la sobrevida sin tratamiento luego de los 2 años de edad ${ }^{1}$. Entre las causas de muerte más frecuentes se encuentran, infecciones, hemorragias y anemia seve$\mathrm{ra}^{3,8}$. Hasta el momento no existe ningún tratamiento médico curativo, siendo éste sólo de soporte y orientado a tratar las complicaciones: transfusiones para el tratamiento de la anemia y la plaquetopenia ${ }^{2}$. Los resultados del tratamiento con corticoides, vitamina D y calcio o PTH son desalentadores ${ }^{1,2}$. El uso de Interferón gamma recombinante humano $1 \mathrm{~b}$ ha demostrado mejoría de la resorción ósea y descenso de las infecciones $^{2,4}$, sin embargo, dado que los efectos son parciales y requiere un tratamiento subcutáneo frecuente, está actualmente desaconsejado ${ }^{4}$.

El trasplante de células madres hematopoyéticas en forma precoz es el único tratamiento efectivo en detener la evolución de la enfermedad, reservándose para las formas más graves ${ }^{2,3,7-10}$. Permite corregir las anomalías óseas, hematológicas e inmunes, al proporcionar células madre capaces de originar osteoclastos maduros normofuncionantes ${ }^{8,10}$. El paciente era portador de mutaciones en gen que no asocia enfermedad neurodegenerativa y presentaba fallo hematológico severo, constituyendo una indicación absoluta de trasplante. Dado que sin tratamiento la enfermedad es letal, se admite el TPH con donantes HLA haploidénticos y con donantes no relacionados ${ }^{8}$. En caso de donantes familiares haploidénticos, la sobrevida es menor (13-
$24 \%)$ y se asocia con riesgos elevados como falla del implante, complicaciones tóxicas e infecciosas ${ }^{1,4,7,8}$. La edad al momento del trasplante es un importante factor pronóstico. Los menores de 2 años tienen menor incidencia de complicaciones peritrasplante y menor afectación neurosensorial ${ }^{8}$.

Se realizó asesoramiento genético dado que es una enfermedad de herencia autosómica recesiva. En esta pareja se puede realizar diagnóstico prenatal o preimplantacional ya que las mutaciones son conocidas. En caso de que el feto esté afectado y decidan continuar con la gestación, es posible programar un TPH precoz con mejor pronóstico ${ }^{2}$.

\section{Conclusiones}

Es prioritario un enfoque multidisciplinario de la OIM. Es fundamental que el pediatra reconozca esta entidad para lograr un diagnóstico correcto y oportuno.

\section{Responsabilidades Éticas}

Protección de personas y animales: Los autores declaran que los procedimientos seguidos se conformaron a las normas éticas del comité de experimentación humana responsable y de acuerdo con la Asociación Médica Mundial y la Declaración de Helsinki.

Confidencialidad de los datos: Los autores declaran que han seguido los protocolos de su centro de trabajo sobre la publicación de datos de pacientes.

Derecho a la privacidad y consentimiento informado: Los autores han obtenido el consentimiento informado de los pacientes y/o sujetos referidos en el artículo. Este documento obra en poder del autor de correspondencia.

\section{Conflicto de intereses}

Los autores declaran no tener conflicto de intereses. 


\section{Bibliografía}

1. Schulz A, Moshous D, Stewart G, Villa A, Sobacchi C. Osteopetrosis. Consensus guidelines for diagnosis, therapy and follow-up. Leiden. ESID and the EBMT Working Party Inborn Errors 2010. https://esid.org/content/ download/15294/420706/file/00_OP_ Guidelines_V3.pdf, última visita: 21-102018.

2. Stark Z, Savarirayan R. Osteopetrosis. Orphanet J Rare Dis. 2009;4:5.

3. Porras O. Osteopetrosis. Rev Med Hosp Nac Niños (Costa Rica). 1999;34:69-75.

4. Steward CG. Hematopoietic Stem Cell Transplantation for Osteopetrosis. Pediatr Clin North Am. 2010; 57:171-80.

5. Horton W, Hecht J. Trastornos debidos a defectos en la reabsorción ósea.
En: Kliegman RM, Stanton BF, St. Geme JW, Schor NF, Behrman RE, eds. Nelson Tratado de Pediatría. 20 ed. Barcelona: Elsevier 2016;3512-13.

6. Mohn A, Capanna R, Delli Pizzi C, Morgese G, Chiarelli F. Autosomal malignant osteopetrosis. From diagnosis to therapy. Minerva Pediatr. 2004;56:1158.

7. Driessen GJA, Gerritsen EJA, Fischer A, et al. Long- term outcome of haematopoietic stem cell transplantation in autosomal recessive osteopetrosis: an EBMT report. Bone Marrow Transplant. 2003; 32:65763.

8. Villa Alcázar M, Benito Bernal A, Díaz Pérez M.A., Madero López L. Trasplante alogénico de médula ósea en osteopetrosis maligna: Nota Clinica. An Esp Pediatr. 1997;47:539-46.
9. Stepensky P, Schulz A, Lahr G, et al. Successful second haploidentical SCT in osteopetrosis. Bone Marrow Transplant: 2011;46:1021-2.

10. Tolar J, Bonfim C, Grewal S, Orchard P. Engraftment and survival following hematopoietic stem cell transplantation for osteopetrosis using a reduced intensity conditioning regimen. Bone Marrow Transp. 2006;38:783-7.

11. Wu CC, Econs M, DiMeglio LA et al. Diagnosis and Management of Osteopetrosis: Consensus Guidelines From the Osteopetrosis Working Group. J Clin Endocrinol Metab. 2017;102:311123.

12. Schulz AS, Classen CF, Mihatsch WA, et al. HLA-haploidentical blood progenitor cell transplantation in osteopetrosis. Blood Journal 2002;99:3458-60. 